\title{
How performance related pay affects productivity and employment
}

\author{
Anne C. Gielen • Marcel J. M. Kerkhofs • \\ Jan C. van Ours
}

Received: 5 March 2008 / Accepted: 26 March 2009/

Published online: 13 May 2009

(C) The Author(s) 2009. This article is published with open access at Springerlink.com

\begin{abstract}
This paper uses information from a panel of Dutch firms to investigate the labor productivity effects of performance related pay (PRP). We find
\end{abstract}

Production editor: Christian Dustmann

A. C. Gielen ( $\varangle)$

Department of Economics, Maastricht University,

P.O. Box 616, 6200 MD Maastricht, The Netherlands

e-mail: A.Gielen@algec.unimaas.nl

M. J. M. Kerkhofs

OSA Institute for Labor Studies, P.O. Box 90153,

5000 LE Tilburg, The Netherlands

J. C. van Ours · M. J. M. Kerkhofs

Department of Economics, Tilburg University,

Warandelaan 2, P.O. Box 90153, 5000 LE Tilburg, The Netherlands

J. C. van Ours

CentER, Department of Economics, Tilburg, The Netherlands

J. C. van Ours

Department of Economics, University of Melbourne, Victoria, Australia

J. C. van Ours

CEPR, London, United Kingdom

J. C. van Ours · A. C. Gielen

IZA, Bonn, Germany

A. C. Gielen

ROA Research Centre for Education and the Labour Market,

Maastricht, The Netherlands 
that PRP increases productivity at the firm level with $9 \%$ and employment growth with $5 \%$.

Keywords Performance related pay $\cdot$ Labor productivity

JEL Classifications C41 • H55 • J64 • J65

\section{Introduction}

Recent developments, such as globalization, have led to increased competition in several markets. In order to face this fierce competition, firms are continuously looking for ways to improve the productivity of their workforce. A popular instrument is performance related pay (PRP), which may stimulate labor productivity for two reasons. First, in situations of asymmetric information about worker's abilities or effort a PRP-scheme can be used to induce workers to exert the right amount of effort (see for example Prendergast 1999 and Lazear 2004). Second, when hiring new workers, piece rates can be used as a screening mechanism to encourage only the most able workers to apply (Lazear 1986).

Over the past decade in the Netherlands the use of performance related pay has increased substantially from $30 \%$ in 1995 to $39 \%$ in 2001 (Table 1). This paper investigates the effect of PRP on the productivity and employment of Dutch firms. In our analysis we account for potential selectivity of PRPadoption, i.e. the case in which more profitable firms are more likely to introduce performance related pay. Our results indicate that PRP increases productivity substantially. This productivity increase may lower marginal costs of producing, which will result in the hiring of additional workers. We also find evidence that the introduction of PRP affects worker flows, with a net

Table 1 Presence of PRP in Dutch firms (\%)

Source: OSA Labor Demand Survey. Sampling weights are used to create numbers that are representative for firm establishments with at least 5 workers

\begin{tabular}{lccccc}
\hline & 1995 & 1997 & 1999 & 2001 & No. of firms \\
\hline Total & 30 & 35 & 40 & 39 & 2786 \\
By firm size & & & & & \\
$\quad<25$ & 32 & 36 & 40 & 35 & 1037 \\
$25-50$ & 29 & 36 & 33 & 49 & 375 \\
$51-100$ & 21 & 31 & 46 & 48 & 399 \\
$>100$ & 29 & 29 & 40 & 53 & 975 \\
By industry & & & & & \\
$\quad$ Manufacturing, & 30 & 34 & 38 & 45 & 738 \\
$\quad$ agriculture & & & & & \\
Construction & 44 & 56 & 56 & 55 & 308 \\
$\quad$ Trade & 36 & 36 & 45 & 41 & 255 \\
$\quad$ Transportation & 16 & 14 & 20 & 39 & 83 \\
$\quad$ Financial services & 31 & 42 & 44 & 36 & 242 \\
$\quad$ Health care & 13 & 6 & 7 & 10 & 593 \\
$\quad$ Other services & 21 & 29 & 25 & 35 & 137 \\
$\quad$ Government & 47 & 48 & 40 & 38 & 224 \\
$\quad$ Education & 14 & 8 & 13 & 9 & 206 \\
No. of firms & 763 & 932 & 722 & 369 & 2786 \\
\hline
\end{tabular}


positive effect on employment. The contribution of this paper to the literature is threefold. First, we add to the small number of studies that investigate the productivity effect of PRP using firm level panel data. Sofar, this was done on a case study basis only (Lazear 2000; Paarsch and Shearer 2000). Second, we show the importance of selection in productivity studies. Finally, we investigate the effect of PRP on employment, distinguishing between the effects on inflow and outflow of workers. We are not aware of previous studies that considered these effects.

The set-up of our paper is as follows. In Section 2 we give a brief overview of previous empirical literature on performance pay and productivity. Section 3 presents our data and in Section 4 we discuss the determinants of PRP. Section 5 contains the results of our empirical analysis. Section 6 concludes.

\section{Literature overview}

PRP can be either an individual scheme, such as a piece rate wage, or a collective scheme, such as profit sharing. Despite the potentially positive productivity effects, PRP may not always increase productivity. In case of teamwork, individual performance is difficult to measure, hence there is an incentive to free-ride. In such a case, group-based incentive schemes may have little effect on individual productivity. Additionally, perverse incentives may arise in case of multitasking. When employees are required to perform several tasks, they will focus only on those activities being rewarded and neglecting other activities. Therefore it is not always clear that the introduction of a PRPscheme will indeed increase productivity.

Some empirical studies on the productivity effects of PRP use information from worker surveys. However, in these surveys, detailed information about productivity is mostly absent. Therefore, wage information is used, a rather crude indicator of individual productivity. For the US, studies using the NLSY data show that PRP is associated with about 5 percent higher wages (e.g. Ewing 1996; Armuedo-Dorantes and Mach 2003). Booth and Frank (1999), using British data find slightly larger effects of 9 percent for men and 6 percent for women.

The lack of an appropriate productivity indicator in worker surveys has given rise to a branch of literature where detailed information from a single firm is used to estimate the productivity effects of PRP. Examples are case studies by Lazear (2000) and Paarsch and Shearer (2000), who find that the introduction of piece rate schemes increased the productivity by 40 and 23 percent, respectively. However these results only hold for the respective firms, and may not be valid for other firms.

Productivity effects estimated in studies that use representative firm surveys are much smaller. An early study by Kruse (1992) finds that the adoption of profit sharing in US manufacturing firms is associated with a $2.8-3.5$ percent productivity increase, while for non-manufacturing companies the increase 
was about $2.5-4.2$ percent. ${ }^{1}$ When profit sharing is measured as proportion of employees covered, the estimated increase is 7.9-8.9 percent and 10.3-11.0 percent, respectively. Similar studies for UK engineering firms (Cable and Wilson 1989) and French manufacturing firms (Cahuc and Dormont 1997) find that the introduction of profit sharing arrangements raises productivity by $3-8$ percent and 2 percent, respectively.

Introducing PRP may affect productivity for two reasons (Lazear 1986). It may extract the right amount of effort from workers - the incentive effect - and it may be used as a screening device to encourage only the most able workers to apply - the sorting effect. Lazear (2000) finds that half of the piece rate induced increase in productivity is due to the incentive effect while the other half is due to the sorting effect, i.e. the inflow of high-productivity workers. Similar incentive and sorting effects are found in Paarsch and Shearer (2000).

\section{Data}

The OSA Labor Demand Panel is a biennial panel firm survey representative for establishments in the Netherlands with at least 5 employees. ${ }^{2}$ This dataset is a refreshment panel for which all organizations that have participated in one wave are approached again two years later for participation in the next wave. Organizations that cannot be contacted or refuse further cooperation ${ }^{3}$ are replaced by a stratified random refreshment sample. The data we use in our empirical analysis are from four consecutive waves covering the period 19952001. In our data 791 establishments are observed twice, 288 three times, 84 four times. The dataset comprises all industries with the sample stratified with respect to the area of economic activity and firm size. ${ }^{4}$

For each firm in the panel we know whether or not a PRP scheme is used. The respondent is asked whether "there is a performance-related pay of any kind in the organization". Unfortunately, we do not know how many workers in the firm receive PRP. Therefore, our PRP-variable is a dummy variable indicating whether or not performance-related payments occur in the firm. Additionally, the dataset contains information on sales and production costs. Respondents in the private sector were asked "if sales measure the

\footnotetext{
${ }^{1}$ The empirical literature shows that generally profit sharing arrangement have smaller productivity effects than piece rate schemes. This may have to do with piece rate schemes being applicable only in situations in which individual output can be monitored easily.

${ }^{2}$ In this paper we will use the terms establishment and firm interchangeably to describe the unit of analysis. The exclusion of such small firms excludes 11 percent of the Dutch labor force, but the prevalence of PRP (denoted as the share of the total wage) is not being different than for workers in larger firms (Arbeidsinspectie 2003).

${ }^{3}$ The panel attrition rate is approximately 40 percent between two waves, 4 percent of which is due to firms closing down or being restructured as a result of a merger or split-up. In the analysis we assume attrition is not selective with respect to the endogenous variables in the application.

${ }^{4} \mathrm{We}$ use sampling weights to obtain figures that are representative for Dutch establishments with 5 or more employees.
} 
volume of all activities in financial terms, what is the level of the sales this year?" Subsequently, they had to report "the percentage of sales that consists of supplies (raw materials, semi-manufactured articles, intermediary supplies and services, outsourcing) that were purchased from other suppliers". Organizations in the non-profit sector were asked to report their "budget" rather than sales, and the "percentage of the budget that consists of purchased products and services, including outsourcing?". The information on sales and production costs together with the number of employees used to obtain this sales volume allows the construction of a measure of per capita value added. Finally, for each firm we have information about the size of worker inflow and outflow on the firm level. ${ }^{5}$

\section{Determinants of PRP}

Table 1 provides some stylized facts on the presence of PRP. As shown especially firms with more than 50 employees increased the use of PRPschemes; from $29 \%$ in 1995 to $53 \%$ in 2001 . Although there is quite some variation in the use of PRP-schemes according to the size of the firm, there is even more variation across industry. These results illustrate the importance of our data, which controls for this variation across industries in the Netherlands, whereas earlier studies using firm level data are rare and, if present, only focus on one particular firm.

Estimates on the presence of PRP in firms using our data as a pooled cross section indicate that PRP schemes are more likely to be adopted in large firms and in the construction sector. ${ }^{6}$ In industries where output is difficult to measure, e.g. health care sector, PRP schemes are less likely to be adopted. Furthermore, during the late 1990s the use of PRP schemes has increased.

To correct for potential selection effects, a logit model is estimated accounting for firm fixed effects: $\operatorname{Pr}\left(P_{i t}=1\right)=\Lambda\left(\alpha_{i}+\beta x_{i t}\right)$ and $\operatorname{Pr}\left(P_{i t}=0\right)=\Lambda\left(-\alpha_{i}-\right.$ $\beta x_{i t}$ ), where $P$ indicates whether or not a firm has a PRP scheme, $x$ is a vector of explanatory variables including firm size and calendar year, $\Lambda$ is an indicator of the logistic cumulative distribution function, $i$ refers to firm, $t$ refers to the year $(1995, \ldots, 2001)$ and the $\alpha_{i}$ represent firm fixed effects. Because of the fixed effects many firms characteristics - all non time-varying characteristics - are accounted for. The parameters are estimated using Chamberlain's conditional likelihood method. This means that the parameters are identified on the subset of observations for which the dependent variable changes at least once over time.

\footnotetext{
${ }^{5}$ It would be interesting to investigate the wage effects of PRP, but unfortunately our dataset lacks appropriate wage information.

${ }^{6}$ These estimates using a binomial logit model are not presented, but are available on request. In the pooled cross-section estimates we also find that PRP schemes are more likely to be present in firms with a high share of employees covered by a collective agreement and in firms with a high share of white collar workers.
} 
Table 2 PRP and productivity

\begin{tabular}{lcr}
\hline & Presence of PRP & Labor productivity \\
\hline$P$ & - & $0.090(0.042) * *$ \\
$\ln ($ firm size $)$ & $0.397(0.266)$ & $-0.881(0.048) * *$ \\
1997 & $0.128(0.144)$ & $0.130(0.031) * *$ \\
1999 & $0.521(0.181) * *$ & $0.164(0.037) * *$ \\
2001 & $0.688(0.225) * *$ & $0.160(0.048) * *$ \\
Observations & 895 & 2786 \\
Firms & 356 & 1164 \\
\hline
\end{tabular}

Note: Presence of PRP: logit model; Labor productivity: linear regression; all estimates contain firm fixed effects; standard errors in parentheses, a ** indicates that the coefficient is different from zero at a 5\% level of significance; reference year is 1995

The parameter estimates are presented in the first column of Table 2. The results indicate that the effect of firm size is insignificant. Apparently, the firm size effect is more a cross-sectional phenomenon than a direct causal effect. There is a clear increase in the use of PRP over time.

\section{Effects of PRP}

\subsection{Labor productivity}

In this section we determine the effect of PRP on productivity of firms. In particular, this paper is the first to investigate the importance of a selection effect in the productivity effects of PRP.

Direct comparison of firms that have a PRP-scheme to those that have not shows that labor productivity is on average $41 \%$ higher in the first group. This difference may however be partially due to selectivity of PRP-adoption, resulting in a different composition of both groups with respect to observed and unobserved characteristics of the firms. To account for these differences we estimate a multivariate regression model that exploits the fact that we have repeated observations for most of the firms. Productivity $y$ in firm $i$ and calendar year $t$ is calculated as: $y_{i t}=s_{i t} *\left(1-m_{i t}\right) / e_{i t}$, where $s$ represents sales, ${ }^{7} m$ the percentage of costs in sales, and $e$ the number of employees of the firm. We estimate the following relationship:

$$
\ln \left(y_{i t}\right)=\gamma_{i}+\gamma_{t}+\beta_{1} \mathrm{P}_{i t}+\beta_{2} \ln \left(e_{i t}\right)+\epsilon_{i t}
$$

where $\gamma_{i}$ is a vector of firm fixed effects, and $\gamma_{t}$ a vector of calendar time fixed effects. Furthermore, the $\beta$ 's are parameters and $\epsilon$ is an error term. We include firm fixed effects in the analysis to control for selectivity in the

\footnotetext{
${ }^{7}$ Sales are denoted in 1995 Dutch guilders; for public sector firms, $s$ indicates budget rather than sales. 
use of PRP schemes. ${ }^{8}$ The parameter estimates are presented in the second column of Table 2. It appears that PRP schemes increase productivity with $9.0 \%{ }^{9}$ Furthermore, firm size has a negative effect on productivity, ${ }^{10}$ while firms become more productive over time.

To investigate the robustness of the PRP productivity effect we performed a detailed sensitivity analysis. As a first variation we have omitted the firm fixed effects and estimated a pooled cross-section model, ignoring the longitudinal character of the data. If no panel data are available it is impossible to distinguish between the incentive effects of PRP and spurious correlation between PRP and productivity that will typically arise if more productive firms are more likely to adopt a PRP scheme. As a result of this potential endogeneity of the PRP variable the estimated effect of PRP would be biased upwards. Indeed, as shown in Table 3, in the pooled cross-section the PRP-productivity effect is estimated as $12.4 \% .^{11}$ Next, we estimated a model in which the firm specific effects were included as random effects. This specification implicitly assumes that PRP can be treated as an exogenous variable in the sense that PRP-adoption is not related to firm-specific characteristics that are related to higher productivity. As in the pooled regression, the effect of PRP will be overestimated if PRP-adoption is subject to endogenous selection. This expectation is confirmed. Testing the fixed effects specification against the random effects specification, we find that the fixed effects model is to be preferred. ${ }^{12}$

Furthermore, we noticed that there was a lot of variation in the reported sales figures indicating potential measurement errors. In order to reduce measurement errors we excluded observations with a large change in sales between two panel observations. We used an indicator variable $z$ defined as $z_{i t}=\ln \left(s_{i t}\right)-\ln \left(\overline{s_{i}}\right)$ where $\overline{s_{i}}$ is the average sales of firm $i$ over the time period available. First, we remove observations for which $\left|z_{i t}\right|>1$. This reduces the sample size but does not affect the productivity effect of PRP in the fixed

\footnotetext{
${ }^{8}$ Additional checks to investigate whether selection into PRP is correlated with other organizational changes (change in skill and age composition of the workforce) show that there is no such relationship.

${ }^{9}$ The results are significant both for private and public sector firms.

${ }^{10}$ The negative effect of firm size in the panel analysis is most likely a short term effect. If firms expand their workforce in the short run productivity goes down.

${ }^{11}$ In these estimates we find that large firms are more productive than small firms. Apparently, in the long run productivity is positively correlated with the size of the workforce. These pooled crosssection estimates already control for the spurious correlation caused by differences in the variables that are included in the model. Including these variables in the regression therefore reduces the PRP coefficient from $41 \%$ to $12.4 \%$, demonstrating that the larger part of the $41 \%$ difference in labor productivity between firms with PRP and firms without PRP should be attributed to differences in observed firm characteristics.

${ }^{12}$ The Hausman test of the random effects specification against the fixed effects specification is 100.95 . This is a $\chi^{2}$-test with 5 degrees of freedom and firmly rejects the random effects specification indicating that the firm specific effects are correlated with the PRP variable.
} 
Table 3 Sensitivity analysis productivity effects

\begin{tabular}{lll}
\hline & PRP parameter & No. of observations \\
\hline Baseline estimate & $0.090(0.042)^{* *}$ & 2786 \\
Pooled cross-section & $0.125(0.044)^{* *}$ & 2786 \\
Random effects & $0.176(0.039)^{* *}$ & 2786 \\
No outliers $\left(\left|z_{i t}\right|<1\right)$ & $0.089(0.041)^{* *}$ & 2773 \\
No outliers $\left(\left|z_{i t}\right|<0.5\right)$ & $0.091(0.039)^{* *}$ & 2663 \\
Hourly productivity & $0.156(0.088)^{*}$ & 1318 \\
Private vs public sector & & \\
$\quad$ PRP - private sector $\left(\left|z_{i t}\right|<0.5\right)$ & $0.077(0.045)^{*}$ & 2663 \\
PRP - public sector $\left(\left|z_{i t}\right|<0.5\right)$ & $0.142(0.083)^{*}$ & \\
\hline
\end{tabular}

Note: The baseline estimate is similar to the one presented in Table 2; standard errors in parentheses, a ** $(*)$ indicates that the coefficient is different from zero at a $5 \%(10 \%)$ level of significance

effects specification. Applying a more strict criterion of removing observations for which $\left|z_{i t}\right|>0.5$ does not change the results either.

Finally, we re-estimated the model correcting for the average number of working hours in the firm. Hence, we used an indicator of productivity per hour worked. This leads to less accurate estimates for two reasons. First, the information on the working hours is available only for a limited number of firms. Second, the average number of hours is rather imprecise as it is measured in categories. As shown, now the PRP-parameter is estimated with less precision but, as shown in the bottom line of Table 3 , still significantly different from zero at $10 \%$.

In the bottom part of the table we distinguish between productivity effects in private sector and public sector firms. Because the number of observations for each of the subgroups is relatively low, measurement error is more likely to affect the results. Therefore, we use only those observations for which $\left|z_{i t}\right|<$ 0.5 . It appears that both effects are not significantly different. When the model is re-estimated without the restriction that $\left|z_{i t}\right|<0.5$ both effects are still not significantly different.

All in all, we conclude from our sensitivity analysis that the estimated productivity effect of PRP of $9 \%$ is quite robust.

\subsection{Worker flows}

The PRP induced productivity increase may be the result of an incentive effect as well as a sorting effect (Lazear 1986). If worker sorting occurs, we expect to find an effect of PRP on worker flows. Furthermore, Table 3 illustrates that that hourly productivity goes up more strongly than overall firm productivity after the introduction of PRP. This shows that the number of working hours increased and because of working hours regulations this implies that additional workers have been hired. To investigate this we estimate worker inflow and 
Table 4 Effects on worker flows

\begin{tabular}{llllll}
\hline & Inflow & Outflow & $\rho$ & -Loglikelihood & Observations \\
\hline A. Baseline model & & & & & \\
$\quad P_{t}$ & $3.86(1.53) * *$ & $1.24(1.10)$ & - & - & 1235 \\
$P_{t-1}$ & $1.27(1.52)$ & $0.50(1.09)$ & $0.66(0.02) * *$ & 8783.2 & \\
$\begin{array}{l}\text { B. Restricted model } \\
\quad P_{t}\end{array}$ & $4.38(1.40)^{* *}$ & $1.44(1.00)$ & $0.66(0.02)^{* *}$ & 8783.6 & 1235 \\
$\begin{array}{l}\text { C. No lagged effects } \\
\quad P_{t}\end{array}$ & $6.39(1.39)^{* *}$ & $1.54(0.69) * *$ & $0.54(0.02)^{* *}$ & 16265.2 & 2112 \\
$\begin{array}{l}\text { D. Restricted model } \\
\quad P_{t}\end{array}$ & $1.25(0.69)^{* *}$ & $1.25(0.69) * *$ & $0.54(0.02)^{* *}$ & 16270.9 & 2112 \\
\hline
\end{tabular}

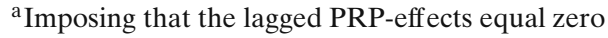

${ }^{b}$ Imposing that the PRP-effect on the inflow equals the PRP-effect on the outflow.

Note: Worker flows: bivariate Tobit model, other explanatory variables are log of firm size and dummies for calendar year and sector; $\mathrm{a} * *$ indicates that the coefficient is different from zero at a $5 \%$ level of significance

worker outflow simultaneously using a bivariate Tobit model, such that $e_{i t}^{i n}=$ $\max \left[0, e_{i t}^{\text {in }}\right]$ and $e_{i t}^{\text {out }}=\max \left[0, e_{i t}^{\text {out }}\right.$ * with:

$$
\begin{gathered}
e_{i t}^{\text {in* }}=\gamma_{j}^{\text {in }}+\gamma_{t}^{\text {in }}+\delta_{1} P_{i t}+\delta_{2} P_{i, t-1}+\gamma_{e}^{i n} \ln \left(e_{i t}\right)+\varepsilon_{i t}^{\text {in }} \\
e_{i t}^{\text {out* }}=\gamma_{j}^{\text {out }}+\gamma_{t}^{\text {out }}+\delta_{3} P_{i t}+\delta_{4} P_{i, t-1}+\gamma_{e}^{\text {out }} \ln \left(e_{i t}\right)+\varepsilon_{i t}^{\text {out }}
\end{gathered}
$$

where $e^{\text {in }}$ is the inflow rate and $e^{\text {out }}$ is the outflow rate with the $\delta$ 's as our parameters of interest. Furthermore the $\gamma_{j}$ 's are fixed effects for industries, the $\gamma_{t}$ 's are fixed effects for calendar years, the $\gamma_{e}$ 's are parameters indicating the effect of firm size and the error terms are assumed to be jointly normally distributed with $\rho=\operatorname{Cov}\left[\varepsilon^{\text {in }}, \varepsilon^{\text {out }}\right]$. Since we expect worker flows to react gradually to the introduction of PRP, we also include a dummy variable for the presence of PRP lagged one period.

Table 4 presents the estimation results. The results in panel A indicate that worker inflow increases by almost 4 percentage points right after the introduction of PRP. In the long run worker inflow is 5 percentage points higher than in firms without PRP. Furthermore, worker outflow increases by more than 1 percentage points initially, and increases in the long run by almost 2 percentage points. However, the parameter estimates for the lagged presence of PRP are insignificantly different from zero. The results in panel $\mathrm{B}$ indicate that we cannot reject the hypothesis that the lagged effects are equal to zero. ${ }^{13}$ Because we can ignore lagged PRP-effects our sample size increases substantially. Panel $\mathrm{C}$ shows that the introduction of PRP increases the inflow with $6.4 \%$ while it increases the outflow with $1.5 \%$. Apparently, the introduction of PRP increases employment growth with almost $5 \%$. To

\footnotetext{
${ }^{13}$ The Likelihood Ratio test statistic equals 0.8.
} 
investigate whether indeed there is permanent employment growth in panel $\mathrm{D}$ we impose the PRP-effects on the inflow and outflow to be of the same size. From a Likelihood Ratio test it appears that we cannot accept the hypothesis that the introduction of PRP does not affect employment growth. ${ }^{14}$

All in all, the introduction of PRP induces worker reallocation which could be evidence of the worker sorting effect predicted by Lazear (1986). Although we cannot observe whether the average ability of worker inflow differs from that of worker outflow we consider this possibility to be very likely. If not, why would worker reallocation occur at all?

\section{Conclusions}

This paper presents an empirical analysis of the productivity and employment effects of PRP. We find that the introduction of PRP increases productivity of firms with about $9 \%$. This may be partly due to an incentive effect and partly due to worker sorting. The increase in productivity does not come at a cost of employment. On the contrary: we find that the inflow of workers increases more than the outflow does, thus generating a net employment growth of 5 percentage points.

Our results with respect to the productivity effects of PRP are quite robust. The fixed effects approach proves to be useful for modeling the causal effect of PRP on productivity. To substantiate the estimated effect it would be worth applying the model to data that contain more detailed information about the types of PRP-schemes and the characteristics of workers involved, information that may be available from linked employer-employee data.

Acknowledgements The authors thank two anonymous referees for their useful comments and the OSA Institute for Labor Studies, for the use of their data.

Open Access This article is distributed under the terms of the Creative Commons Attribution Noncommercial License which permits any noncommercial use, distribution, and reproduction in any medium, provided the original author(s) and source are credited.

\section{References}

Arbeidsinspectie (2003) Arbeidsvoorwaardenontwikkelingen in 2002 - een onderzoek naar de ontwikkelingen in de bruto-uurlonen en de extra uitkeringen. Ministerie van Sociale Zaken en Werkgelegenheid, The Hague

Armuedo-Dorantes C, Mach T (2003) Performance pay and fringe benefits. Int J Manpow 24(6):672-698

Booth AL, Frank J (1999) Earnings, productivity, and performance-related pay. J Labor Econ 17(3):447-463

\footnotetext{
${ }^{14}$ The LR test statistic equals 11.4 which is significantly different from zero at a $1 \%$ level. Note also that if we re-estimate the fixed effects productivity model on the sample of 2112 firms, we find a parameter estimate (standard error) of $0.088(0.051)$.
} 
Cable J, Wilson N (1989) Profit-sharing and productivity: an analysis of UK engineering firms. Econ J 99:366-375

Cahuc P, Dormont B (1997) Profit sharing: does it increase productivity and employment? A theoretical model and empirical evidence on French micro data. Labour Econ 4:293-319

Ewing BT (1996) Wages and performance-based pay: evidence from the NLSY. Econ Lett 51:241246

Kruse DL (1992) Profit sharing and productivity: microeconomic evidence from the United States. Econ J 102(410):24-36

Lazear EP (1986) Salaries and piece rates. J Bus 59:405-431

Lazear EP (2000) Performance pay and productivity. Am Econ Rev 90(5):1346-1361

Lazear EP (2004) Output-based pay: incentives, retention or sorting. In: Polachek SW (ed) Research in labor economics. JAI Press, Stanford, pp 1-25

Paarsch HJ, Shearer B. (2000) Piece rates, fixed wages, and incentive effects: statistical evidence from payroll records. Int Econ Rev 41(1):59-92

Prendergast C (1999) The provision of incentives in firms. J Econ Lit 37:7-63 